\title{
EFFECTS OF COMPONENT AND THICKNESS OF METAL LAYER ON RESPONSE FUNCTIONS OF BONNER SPHERE EXTENDED SPECTROMETER USING MCNP CALCULATION
}

\author{
Mai Nguyen Trong Nhan" ${ }^{a^{*}, \text { Trinh Thi Tu Anh }}$
}

\begin{abstract}
${ }^{a}$ The Faculty of Nuclear Engineering, Ulsan National Institute of Science and Technology, Ulsan, South Korea

${ }^{b}$ The Research Management and International Cooperation Department, Dalat University, Lamdong, Vietnam
\end{abstract}

\author{
Article history \\ Received: November $15^{\text {th }}, 2016 \mid$ Received in revised form: November $30^{\text {th }}, 2016$ \\ Accepted: December $12^{\text {th }}, 2016$
}

\begin{abstract}
The response functions of the Bonner Sphere Extended spectrometer were calculated using the MCNP program. For incident neutrons above $10 \mathrm{MeV}$, Tungsten was an excellent heavy material layer as it yielded the highest response among tested materials. As for the effect of isotopes' abundance and thickness of the metal layer, the differences in the response function could be neglected in the high-energy region (above several MeV), but the thickness of the heavy-metal layer had a considerable effect on the response. Recommended thickness for Bonner Sphere Extended spectrometers was also discussed.
\end{abstract}

Keywords: Bonner Sphere Extended spectrometer; Isotope abundance; Metal thickness; Response.

\section{INTRODUCTION}

Bonner Sphere spectrometer is used to measure neutron energies stretching from $\mathrm{eV}$ to several $\mathrm{MeV}$. With higher neutron energies, the performance of conventional Bonner Sphere spectrometers (BSS) declines dramatically as a result of leakage and low neutron absorption cross section. Bonner Sphere Extended spectrometers (BSE) were introduced to address this issue. By adding a layer of heavy-metal, the response at high energy level (above 10MeV) was improved. This heavy-metal layer acted as a neutron multiplier as high energy neutron induced ( $\mathrm{n}, \mathrm{xn}$ ) reactions. Response functions of BSE were an interest in many works, and the recent results could be found from the articles by Burgett (2008); Howell, Burgett, Wiegel, and Hertel (2010); and Vylet (2002). Still, the 
configuration of BSE used in each research was slightly different. In the research by Howell et al. (2010) and Burgett (2008), BSE was equipped with the LiI(Eu) detector, and the metal layer was assigned as 1 in thick of copper, lead and tungsten. The BSE used at Stanford Linear Accelerator Center (SLAC), on the other hand, was equipped with ${ }^{3} \mathrm{He}$ detector and the metal layer was only $1 \mathrm{~cm}$ of lead (Vylet, 2002). The value of metal thickness was chosen by each author without any reasonable explanation.

The effect of the metal thickness on the BSE response function has not been analyzed. However, the authors of this paper suggested that the metal thickness would have some effect on the response of BSE because of the following reasons:

- For heavy metal, high-energy neutrons either underwent backward scattering or induced $(\mathrm{n}, \mathrm{xn})$ reactions. These two events will be improved by increasing the thickness of the metal layer. However, with a specific thickness, there would be a dominant one.

- $\quad$ Besides, with differed metal thickness, neutrons born from $(\mathrm{n}, \mathrm{xn})$ reactions inside the metal layer would have different possibility to reach the detector.

In addition, isotopes of an element with different cross sections at the same energy level might affect the spectrometer's response as well. The aim of this study was to determine the effect of isotopes' abundance and thickness of metal layer on the response of a BSE spectrometer. The calculated results for the suitable metal thickness were then discussed. In radiation detection and measurements, the optimal thickness for the heavy metal layer in BSE would be necessary. The spectrometers included the 5, 7, 8, 12 inchesdiameter spheres with a layer of copper, tungsten or lead. Calculations were carried out using the Monte Carlo (2003) simulation program MCNP5 and MCNPX.

\section{MATERIAL AND METHOD}

\subsection{Spectrometer modeling}

A realistic model of the detector, including the $0.4 \mathrm{~cm} \times 0.4 \emptyset \mathrm{cm}$ scintillator, the light pipes, the detector's cask, and the polyethylene spheres was designed following 
specifications of the commercially available Ludlum system: Model 42-5 (Ludlum Measurements, 2006). In this research, the scintillator was modeled as Li-glass made of ${ }^{6} \mathrm{Li},{ }^{7} \mathrm{Li}$ and $\mathrm{SiO}_{2}$ instead of $\mathrm{LiI}(\mathrm{Eu})$; The $\mathrm{Ce}^{3+}$ impurities were excluded (Brittingham 2010). The Li-glass scintillators are extremely robust being resistant to all organic and inorganic chemicals except hydrofluoric acid and strong alkalis and can be used in temperatures ranging from $-200^{\circ} \mathrm{C}$ to $250^{\circ} \mathrm{C}$. This allows them to be used in conditions which prohibit the use of other scintillation materials like $\mathrm{LiI}(\mathrm{Eu})$. A layer of heavy metal (lead, copper or tungsten) was added in addition to the polyethylene sphere as shown in Figure 1.
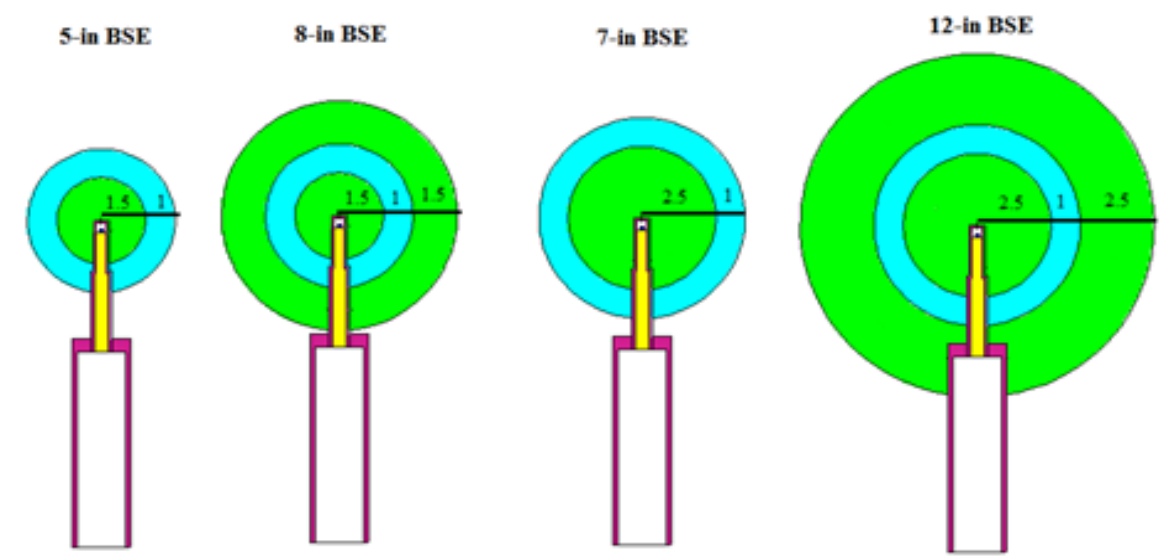

Figure 1. Bonner Sphere Extended spectrometers

Note: Green parts were polyethylene and the blue ones were the metal layer

\subsection{Execution of MCNP}

Each model was irradiated with a parallel neutron beam produced by a diskshaped neutron source having the same diameter to the sphere; Irradiations were carried out using 30 neutrons bin (1E-08 MeV to $150 \mathrm{MeV}$ ) suggested by Brittingham (2010). MCNP5 was used for neutron under $20 \mathrm{MeV}$ as MCNP5 satisfied only to around $20 \mathrm{MeV}$; MCNPX version 2.5.0 was employed to extend the energy range from $20 \mathrm{MeV}$ to 150 $\mathrm{MeV}$ using the LA150 cross section library. In all calculations, the response was calculated based on the number of ${ }^{6} \mathrm{Li}(\mathrm{n}, \alpha)^{3} \mathrm{H}$ reactions occurring in the scintillator per each neutron emitted by the disk-shaped neutron source according to Hector et al. (2008). 
The number of alpha particle produced in the Li-glass was calculated by the multiplier card FM4 (Monte Carlo, 2003). Geometry splitting (Shultis \& Faw, 2011) was employed as a variance reduction technique.

The metal layer was first designed as a 1-in thick layer with natural isotopes' abundances. When these simulations were completed, the metal layer was assumed to consist of only one stable isotope (i.e. $100 \%{ }^{206} \mathrm{~Pb}$ or $100 \%{ }^{207} \mathrm{~Pb}$ ). Such simulations were used to determine the effect of heavy metal isotopes' abundance.

For the effect of metal thickness, the metal layer comprised of stable isotopes as in the first case. However, the thickness of this metal layer varied, namely 0.5 in, 1 in, 1.5 in and 2 in.

\section{RESULTS AND DISCUSSION}

\subsection{Effects of isotopes' abundance}

The discussion of 5-in BSE and 8-in BSE was grouped together as the two BSE had the same polyethylene core (3 in), so did 7-in BSE and 12-in BSE (5-in polyethylene core).

\subsubsection{5-in BSE and 8-in BSE}

At $2.10^{-5} \mathrm{MeV}$, for (n, gamma) reactions, the absorption cross sections are rather high for all tungsten isotopes. As a result, the response of 5-in BSE with the tungsten layer at this energy was nearly zero. This effect was trivial for the 8-in one as it was covered with a layer of polyethylene.

Above $10 \mathrm{MeV}$, the energy of neutrons is high enough to induce $(n, x n)$ reactions. Newly born neutrons from metal layer compensated for leakage and were likely to reach the detector, leading to the increasing in response. For high energy neutron, the response functions of 5-in BSE with tungsten and 8-in BSE with lead were rather like each other. 


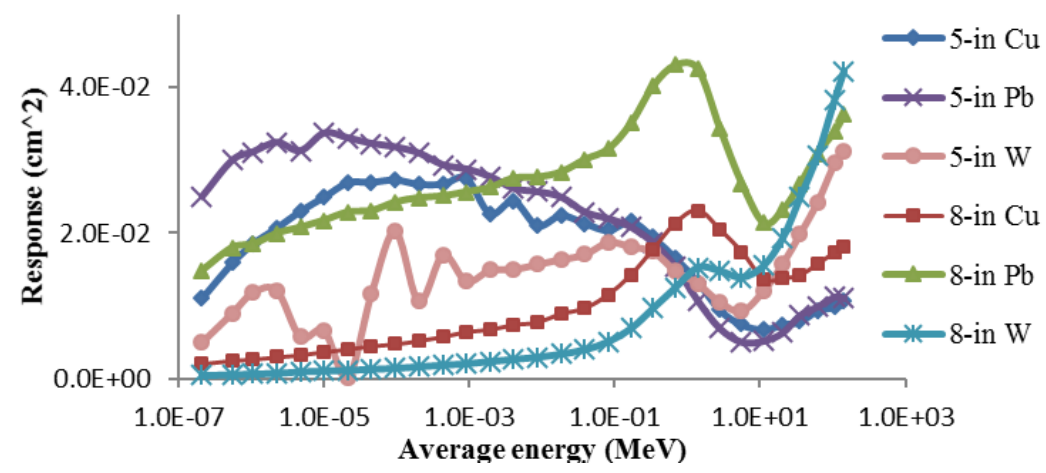

Figure 2. Response functions of 5-in and 8-in BSE

\subsubsection{7-in BSE and 12-in BSE}

Below $0.1 \mathrm{MeV}$, the response of 12-in BSE was nearly zero. For measurement in such energy range, these BSE were inefficient. BSE with the tungsten layer still yielded the highest response for neutron over $10 \mathrm{MeV}$. As seen from Figure 3, the response of the 12-in BSE with a tungsten layer was the highest one. In addition, the 12-in BSE with a lead layer had nearly the same response as the 7-in BSE with a tungsten layer. As a result, these two BSE could be interchangeable in neutron measurement (50 to $150 \mathrm{MeV}$ ).

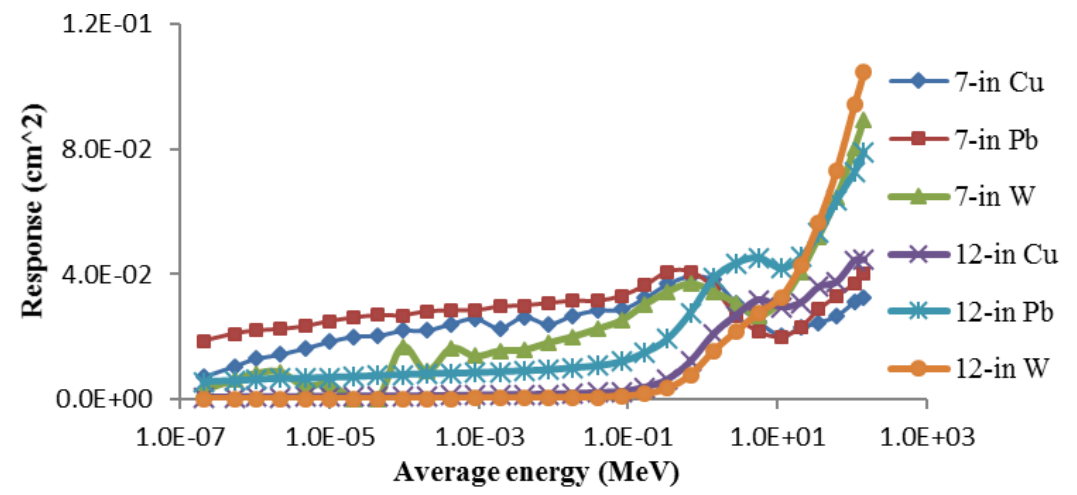

Figure 3. Response functions of 7-in and 12-in BSE

The effect of isotopes' abundance of the metal was also taken into consideration. However, the difference in the response function was insignificant. The isotopes' abundance of metal had virtually no effect on the performance of the spectrometer.

From the obtained result, lead was a very good heavy material for BSE spectrometer as it was the metal that showed the least variation in spectrometer response functions regardless of isotopes' abundance. Copper was not an optimal material as the response of BSE with the copper layer was lower than the response of BSE with other 
metal layers. However, among the three tested metals, copper was the lightest one, with the density being only $8.89 \mathrm{~g} / \mathrm{cm}^{3}$.

Tungsten was the heaviest metal in use $\left(19.3 \mathrm{~g} / \mathrm{cm}^{3}\right)$, and in terms of response functions, the tungsten layer was the best choice for neutron above $10 \mathrm{MeV}$. From this level on, the response of all BSE with the tungsten layer surged and surpassed all the response of the same size BSE with the copper or lead layer.

\subsection{Effect of metal thickness}

At low energy level, neutron could not induce the $(n, x n)$ reactions and most scattered. The scattering effect increased with the increase of metal thickness. With high neutron energy, the thicker metal layer provided higher opportunity for neutron to be absorbed and induced $(\mathrm{n}, \mathrm{xn})$ reactions.

\subsubsection{Effects of metal thickness on 5-in BSE}

Above $10 \mathrm{MeV}$, response of 5-in BSE with 0.5 in metal was the lowest. In Figure 4 , for neutron energy lower than $2 \mathrm{MeV}$, response functions of lead or tungsten showed good agreement regardless of metal thickness. In the energy bin of $5 \mathrm{MeV}$ to $10 \mathrm{MeV}$ was quite special as it was the range where all the response functions increased. In case of the heavy metal layer, high energy neutrons started to induce $(\mathrm{n}, \mathrm{xn})$ reactions. For the energy region of above $10 \mathrm{MeV}$, this effect became important. A 2-in thick of heavy metal was proposed for 5-in BSE.

For this BSE, the fluctuation in the low energy region was not severe as 5-in BSE with the tungsten layer and 5-in BSE with the copper layer (Figure 4). A thicker inner polyethylene sphere for 7-in BSE (5in compared to 3 in) was a reason for this. After traversing a longer distance in the moderator, neutron could have a spread of energy due to a myriad of stochastic events (broadening effect). 


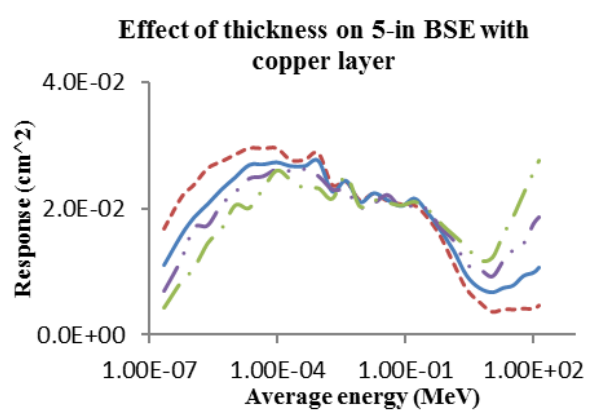

Effect of thickness on 5-in BSE with tungsten layer

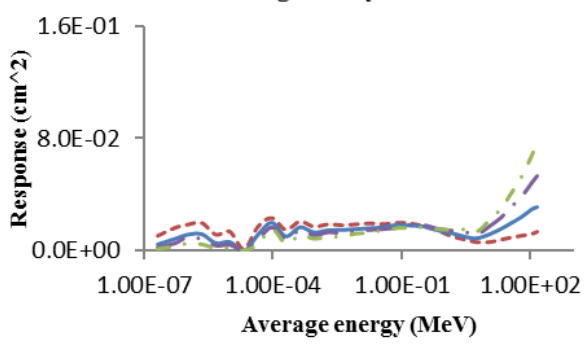

Effect of thickness on 5-in BSE with lead layer

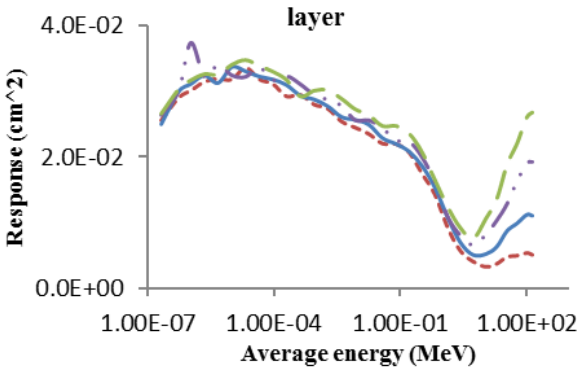

Legend

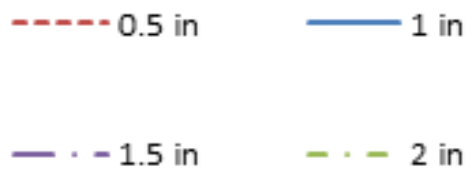

Figure 4. Effect of thickness on 5-in BSE

Effect of thickness on 7-in BSE with copper layer

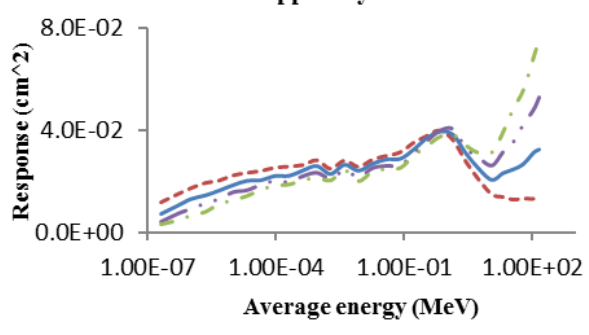

Effect of thickness on 7-in BSE with tungsten layer

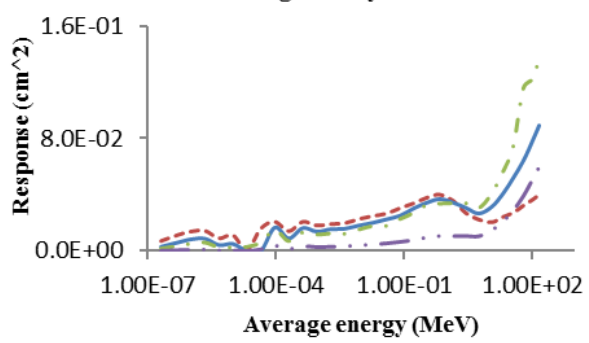

Effect of thickness on 7-in BSE with lead layer

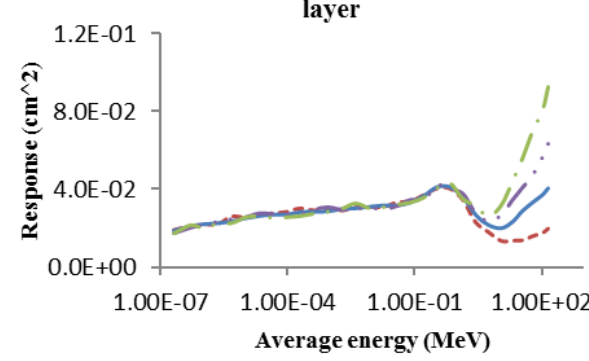

Legend

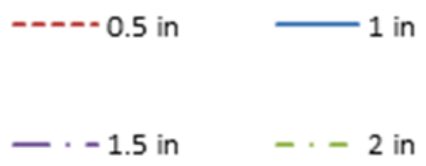

Figure 5. Effect of thickness on 7-in BSE

Notably, 7-in BSE with 1-in tungsten layer had a closed response to the 7-in BSE with 2-in tungsten layer. For this BSE, 1 in thick of tungsten was suggested. 


\subsubsection{Effects of thickness on 8-in BSE}

The energy range of $5 \mathrm{MeV}$ to $10 \mathrm{MeV}$ was also the changing range as stated in Section 3.2.1. For 8-in BSE with lead layer, except the 0.5-in case, the effect of metal thickness was hardly recognized above $10 \mathrm{MeV}$. For 8-in BSE with lead layer, 1-in thick of lead was good enough. Besides, 1.5 in thick of tungsten for this BSE weighted up to $136 \mathrm{~kg}$. Hence, 1 in of tungsten was reasonable.
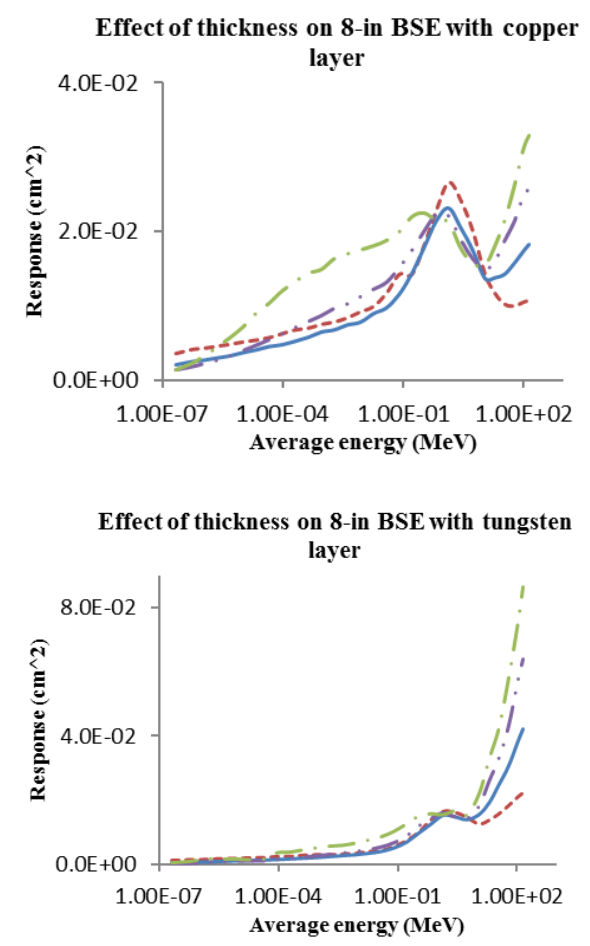

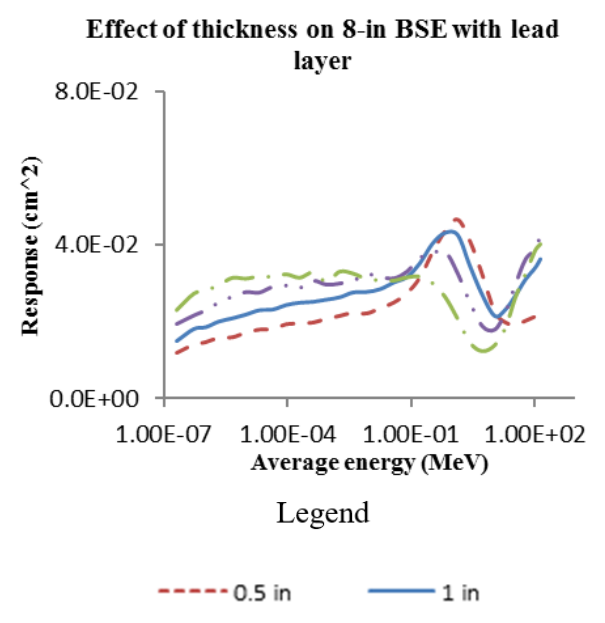

Figure 6. Effect of thickness on 8-in BSE

\subsubsection{Effects of metal thickness on 12-in BSE}

When the diameter of the BSE increased, the responses at low energy regions decreased as a result of radiative capture reactions, low energy neutrons were unlikely to reach the detector. For 12-in BSE, they were useless in this energy range. The following discussion only concentrated on high energy level (above 10MeV). For 12-in BSE, the 0.5 -in line was much lower than others.

The 12-in BSE with 2-in copper layer was special as above $100 \mathrm{MeV}$, there was a sign of response decline as shown in the first chart of Figure 7. For the other two materials, the 1.5-in line and 2-in line were close to each other. Besides, the response functions of 
BSE with tungsten layer or lead layer were very smooth above $10 \mathrm{MeV}$. For high energy measurement, such smooth lines would offer better data to get more accurate results during spectra unfolding procedure. Unfortunately, in view of weight problem, the thickness of heavy metal layer like lead or tungsten should be $1 \mathrm{in}$. Copper is lighter, its thickness could be extended to 1.5 in.
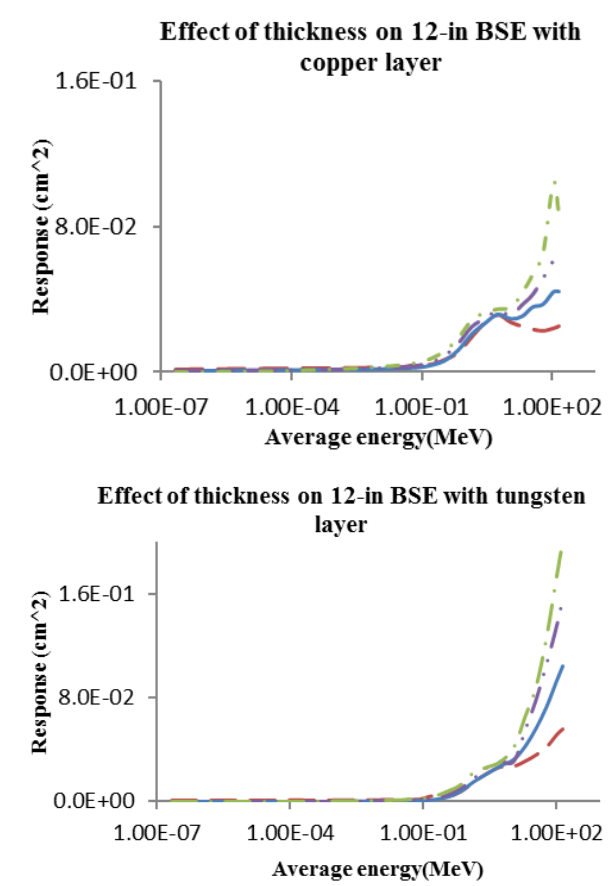

Figure 7. Effects of thickness on 12-in BSE
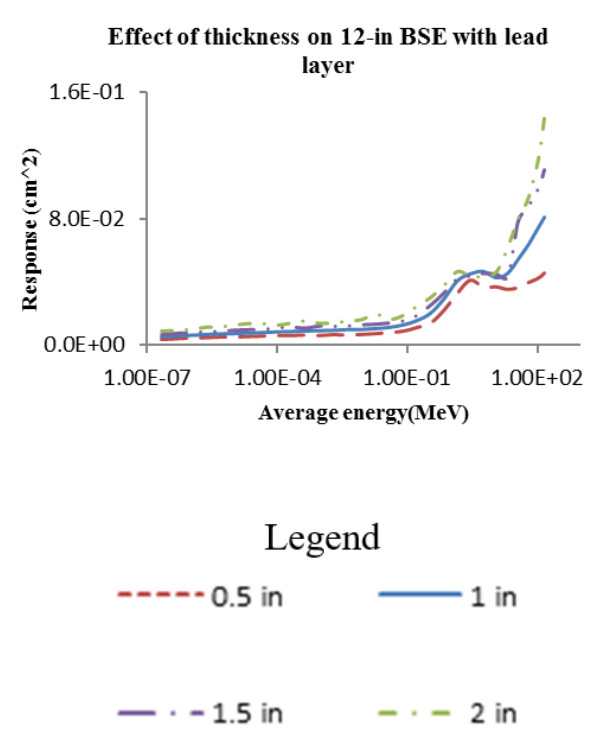

\section{CONCLUSION}

In this work, response functions of BSE spectrometer with copper, lead and tungsten layer were calculated. The effects of metal thickness were also taken into consideration. The main results were stated as follows:

- Isotopes' abundance of the metal layer had no significant effect on the response of spectrometers;

- Tungsten was an ideal heavy metal for BSE spectrometer;

- The recommendation for metal thickness of each BSE was discussed. As for 5in BSE, 2-in of metal was recommended. For other BSE spectrometers, 1-in of 
metal was already good for the job;

- The decline of 12-in BSE with 2-in copper layer at $105 \mathrm{MeV}$ (Figure 7) was difficult to grasp.

\section{REFERENCES}

Brittingham, J. M. (2010). The effect of Bonner Sphere Borehole orientation on neutron detector response. (Master Thesis), The University of Tennessee, USA. Retrieved from http://trace.tennessee.edu/utk_gradthes/775

Burgett, E. A. (2008). A broad-spectrum neutron spectrometer utilizing a high energy Bonner Sphere Extension. (Master Thesis), The Georgia Institute of Technology, USA. Retrieved from https://www.ncbi.nlm.nih.gov/pubmed/22888283

Hector, R. V. C., Eduardo, G., Eduardo, M., \& Alfredo, L. (2008). A Monte Carlo calculation of the response matrix of a Bonner Sphere spectrometer. Revista Mexicana de Fisica, 54(1), 57-62.

Howell, R. M., Burgett, E. A., Wiegel, B., \& Hertel, N. E. (2010). Calibration of a Bonner Sphere Extension (BSE) for high-energy neutron spectrometry. Radiation Measurement, 45(10), 1233-1237.

Ludlum Measurements. (2006). LUDLUM model 42-5. Retrieved from http:// www.qsl.net/k0ff/old files/1C Working Copy/yyy/LUDLUM MANUALS/M425mar89.pdf

Monte Carlo. (2003). MCNP5 Manual. Retrieved from https://www.nucleonica.com/ wiki/images/8/89/MCNPvolI.pdf.

Shultis, J. K., \& Faw, R. E. (2011). A primer for MCNP5. Manhattan, USA: Kansas State University.

Vylet, V. (2002). Response matrix of an extended Bonner Sphere system. Nuclear Instruments and Methods in Physics Research, 476(1-2), 26-30. 


\title{
ẢNH HƯỞNG CỦA THÀNH PHẦN VÀ BỀ DÀY LỚP KIM LOẠI LÊN HÀM ĐÁP ỨNG CỦA PHỔ KẾ BONNER SPHERE EXTENDED BẰNG TÍNH TOÁN MÔ PHỎNG MCNP
}

\author{
Mai Nguyễn Trọng Nhâna*, Trịnh Thị Tú Anh ${ }^{\mathrm{b}}$
}

${ }^{a}$ Khoa Kỹ thuật Hạt nhân, Viện Khoa học và Công nghệ Quốc gia Ulsan, Ulsan, Hàn Quốc ${ }^{b}$ Phòng Quản lý Khoa học - Hợp tác Quốc tế, Truờng Đại học Đà Lạt, Lâm Đồng, Việt Nam

*Tác giả liên hệ: Email: trongnhan217@gmail.com

\author{
Lịch sử bài báo \\ Nhận ngày 15 tháng 11 năm 2016 | Chỉnh sửa ngày 30 tháng 11 năm 2016 \\ Chấp nhận đăng ngày 12 tháng 12 năm 2016
}

Tóm tắt

Hàm đáp ứng của phổ kế Bonner Sphere Extended (BSE) được tính toán dựa trên phần mềm mô phỏng MCNP. Trên $10 \mathrm{MeV}$, Wolfram là vật liệu tốt nhất vì lớp lót Wolfram cho đáp úng cao nhất trong các kim loại được thư nghiệm. Sự khác biệt về độ giàu các đồng vị trong lớp kim loại hầu nhu không gầy ảnh hưởng đến đáp ứng của phổ kế ở vùng năng lương cao (trên vài $\mathrm{MeV}$ ). Bề dày của lớp kim loại có ảnh hưởng đáng kể đến đáp úng của phổ kế. Bề dày thích hợp cho mỗi phổ kế Bonner Sphere Extended cũng được thảo luận trong nghiên cưu này.

Từ khóa: Bề dày kim loại; Đáp ứng; Độ giàu đồng vị; Phổ kế Bonner Sphere Extended. 